\title{
Snake parasitism in an urban old-growth forest
}

\author{
Jon R. Davis • Sarah A. Boyle • Adiha A. Khan • \\ Anna L. J. Gay • John M. Grisham • Laura E. Luque
}

Published online: 24 April 2012

(C) The Author(s) 2012. This article is published with open access at Springerlink.com

\begin{abstract}
Urban-associated changes can have immediate or long-term consequences on animal populations. Such changes may be assessed through parasite prevalence and abundance in wildlife hosts, as urbanization can influence parasitism and disease transmission in wildlife. Snakes are widespread and diverse vertebrates that often persist in urban environments; however, parasitism of snakes in urban environments has yet to be studied, leaving the roles of snakes in parasite transmission uncharacterized. Field ecology, microscopy, molecular techniques, and geographic information science (GIS) were integrated to characterize parasitism of snakes in an urban old-growth forest park. The species, sex, mass, length, location, and prevalence of ecto-, hemo-, and fecal parasites were determined for 34 snakes of 6 species. Ectoparasites (mite), hemoparasites (Hepatozoon spp.), and fecal parasites (Entamoeba spp., Trichomonas spp., Strongloides spp., and an unidentified helminth) were detected in snakes and $64.7 \%$ of snakes were infected by at least one of these parasites. Parasite infections were generally not related to the sex, age, or body condition of snakes. The locations of infected snakes were used to produce risk maps indicating where parasite prevalence is predicted to be greatest. The analysis of these maps indicated that snakes with fecal parasites were closer than non-infected snakes to the edge of the forest. This study confirms that snakes may be important parasite hosts or reservoirs in parasite transmission pathways in urban environments and it provides an integrative multidisciplinary approach that may be used to monitor parasitism dynamics in other urban wildlife areas.
\end{abstract}

Keywords Agkistrodon $\cdot$ Ectoparasite $\cdot$ Fecal $\cdot$ Forest fragment $\cdot$ Hemoparasite $\cdot$ Hepatozoon

\section{Introduction}

Currently more than $50 \%$ of the global human population lives in urban areas and urbanization is expected to increase as the global population climbs towards 9 billion by

Jon R. Davis, Sarah A. Boyle and Laura E. Luque contributed equally to this project

J. R. Davis · S. A. Boyle • A. A. Khan • A. L. J. Gay • J. M. Grisham • L. E. Luque $(\bowtie)$

Biology Department, Rhodes College, Memphis, TN 38112, USA

e-mail: luquedejohnsonl@rhodes.edu 
2050 (United Nations Population Division 2010). As urbanization intensifies, habitat modifications and fragmentation will continue and as a result, local floral and faunal communities may experience decreased species richness (McKinney 2008; Walker et al. 2009), shifts in trophic dynamics due to reduced top-down controls and increased productivity (Faeth et al. 2005), or behavioral modifications (Riley et al. 2003; Ditchkoff et al. 2006), among other things. Mechanisms underlying such responses to urbanization have recently been examined (Shochat et al. 2006), yet effects of urbanization on many animal species remain poorly understood because the majority of published studies have examined conspicuous models, including birds (Chace and Walsh 2006; Slabbekoorn and Ripmeester 2008), relatively large mammals (LoGiudice et al. 2003; Riley et al. 2003; Randa and Yunger 2006; Page et al. 2008), and amphibians (Riley et al. 2005; Rubbo and Kiesecker 2005; Parris 2006). These studies have revealed tremendous interspecific variation in responses to urbanization. For example, urbanization may influence vocalizations in some birds (Leonard and Horn 2008; Slabbekoorn and Ripmeester 2008; Mendes et al. 2011), the timing of nesting in others (Schoech and Bowman 2001), and cause local extinction in others (Blair 2001; Marzluff 2001; McKinney 2008). Thus, comparative studies on a wider variety of species are needed.

Parasitism is a successful and well-known life strategy with numerous ecological and physiological impacts (Marcogliese 2005; Preston and Johnson 2010). Urbanization likely has ecologically relevant effects on host-parasite interactions because it alters the composition and distribution of suitable wildlife habitat, which can constrain species' distributions and alter transmission rates of wildlife parasites (Bradley and Altizer 2007). Moreover, urbanization results in loss of biodiversity (McKinney 2008; Walker et al. 2009) and decreased biodiversity frequently increases transmission of animal and plant infectious diseases (Keesing et al. 2010). Finally, efforts to control arthropod vectors (e.g. mosquitos) in urban areas may further disrupt transmission of parasites among wildlife hosts. Parasites can be used as bio-indicators of environmental impact, including urbanization (Vidal-Martínez et al. 2010), yet a notable gap exists in our understanding of ecological and evolutionary significance of host-parasite interactions for most species (Deviche et al. 2001; Vitt and Caldwell 2009). Thus, research is needed to elucidate these relationships, particularly in urban environments.

Snakes are a diverse group of ectothermic predatory vertebrates that possess several characteristics which may make them important in urban parasite transmission pathways. Notably, snakes are known to host a variety of parasites (Brown et al. 2006; Telford 2009) and often persist and even thrive in urban environments, including urban parks (Shine and Koenig 2001; Burger et al. 2004; Pattishall and Cundall 2009; Smith et al. 2009; Vignoli et al. 2009). Moreover, snakes vary tremendously in size, fill numerous ecological niches, occupy a variety of trophic levels in ecosystems, and tend to live longer than most endothermic hosts (Greene 1997). Therefore snakes provide an excellent opportunity to study parasitism in an urban environment.

A multidisciplinary approach that combined field ecology, microbiology, molecular biology, and geographic information science (GIS) was used to provide an integrative assessment of snake parasitism in an old-growth urban forest in Memphis, Tennessee. The specific objectives of this study were to: 1) identify the community compositions of snakes and the ecto-, hemo-, and fecal parasites they host, 2) assess relationships among parasite prevalence and individual snake characteristics (i.e., sex, age, body condition), and 3) determine the spatial distribution of snakes and factors that may influence parasite prevalence (i.e., distance to the forest edge, the nearest neighboring snake, or nearest neighboring parasitized-snake). The results of this study provide a novel assessment of the parasite community in urban snakes, which may contribute to future assessments of the roles snakes play in parasite transmission in an urban environment. 


\section{Methods}

Study site

The study was conducted in Overton Park, a 140-ha park established in 1901 in urban Memphis, Tennessee (Fig. 1a). Overton Park contains a 70-ha old-growth oak-hickory forest fragment surrounded primarily by residential and commercial areas (Fig. 1b) and is listed on the National Register of Historic Places (NRIS 79002475). A 1-km buffer surrounding the urban forest fragment consists of the following National Land Cover Dataset (NLCD 2001) classes: water $(0.1 \%)$, forest $(1.9 \%)$, developed: open space (6.9\%), developed: low intensity $(50.5 \%)$, developed: medium intensity (33.8\%), and developed: high intensity (6.9\%).

Snake sampling

Snakes were collected during walking surveys of forested areas and the paved roads and dirt paths that transect the forest. Surveys were conducted in 2008 (September), 2009 (AprilOctober) and 2010 (May-August) between 0600 and $0200 \mathrm{~h}$, depending on snake activity periods. Typically, two researchers (JRD and JMG) conducted approximately three 4-hour surveys weekly during the study for an estimated sampling effort of $24 \mathrm{~h}$ weekly $(1,272 \mathrm{~h}$

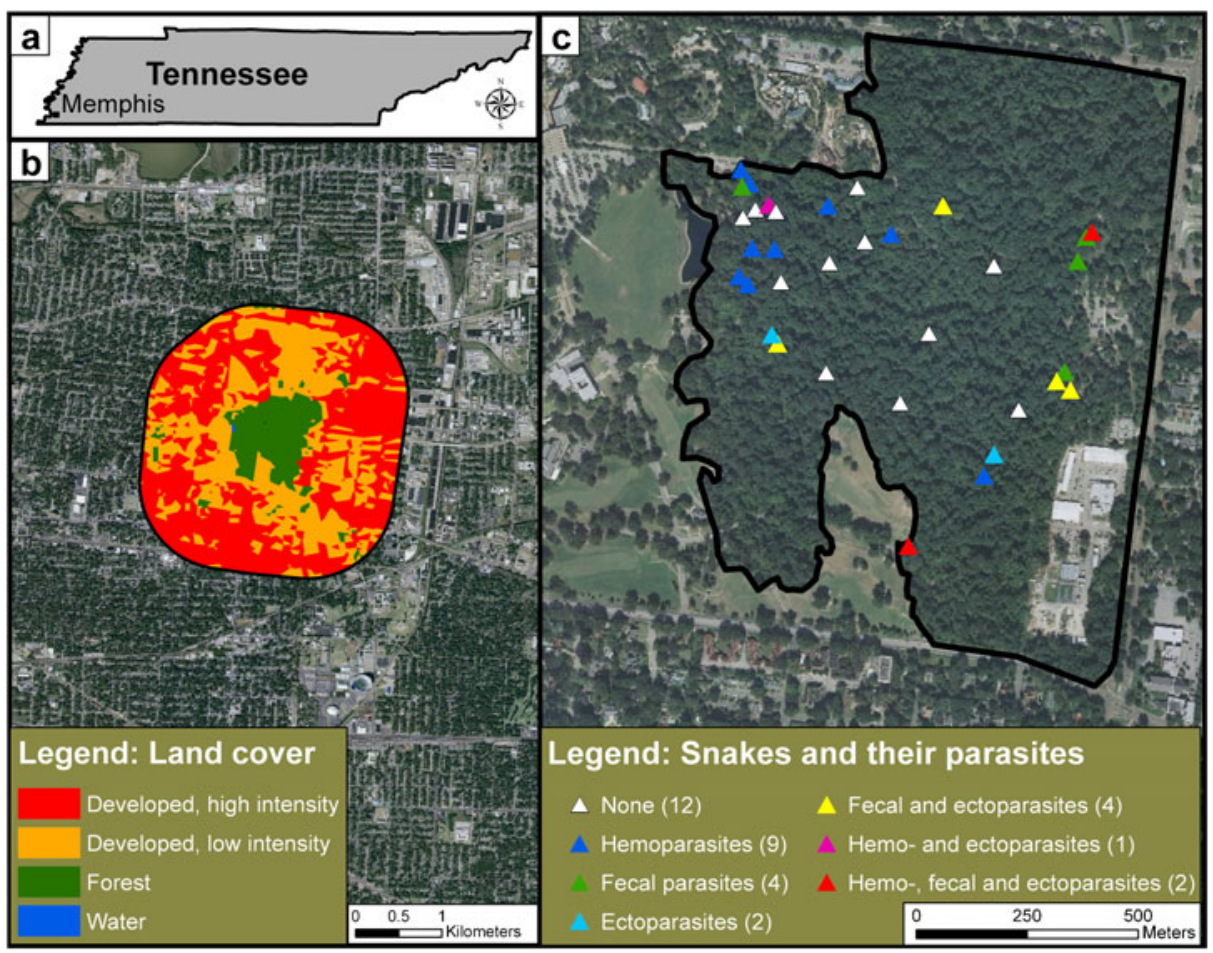

Fig. 1 The study site was an urban forest fragment (a) located in Memphis, Tennessee, and (b) surrounded primarily by developed areas (e.g., houses and apartment buildings, commercial buildings). Snakes used for this study were found (c) within the urban forest, and $64.7 \%$ of the snakes had hemoparasites, ectoparasites, or fecal parasites, or a combination of these parasites 
total) and every effort was made to equally survey all areas of the 70-ha forest. When each snake was encountered, a handheld global positioning system (GPS) unit (model 60CsX, Garmin International Inc., Olathe, KS) was used to record the specific location of each individual, and the species, sex, and age class (adult or juvenile) of each snake were determined. Body mass $( \pm 2.0 \mathrm{~g})$ and snout-to-vent length $(\mathrm{SVL} ; \pm 1.0 \mathrm{~mm})$ were measured and used to calculate body condition index (BCI) for each individual as the residual score from the general linear regression of ln-transformed mass against ln-transformed SVL (Weatherhead and Brown 1996; Waye and Mason 2008). BCI can be used to compare relative available energy reserves among snakes (Shine and Madsen 1997; Aubret et al. 2002; Waye and Mason 2008); moreover, BCI is inversely related to glucocorticoid production in snakes, which can be used as a reliable indicator of chronic stress (Moore et al. 2001). BCI for each snake was classified as positive if it exceeded the mean value for all individuals or negative if the BCI fell below the mean, and these values were then used in statistical analyses described below. In addition, samples were collected as described below to assess ecto-, hemo-, and fecal parasitism of each snake. Prior to release, a black marker was used to temporarily mark scales near the vent so that the same individual would not immediately be sampled again. The copperhead snake (Agkistrodon contortrix) was very common (see Table 1) and thus more likely to be recaptured, so a passive integrative transponder (PIT) tag (Biomark, Boise, ID) was injected intramuscularly into each individual to provide a permanent unique identification number. Snakes were processed and released at the site of collection immediately.

Parasite collection and analyses

\section{Ectoparasites}

When each snake was processed, a handheld $10 \times$ magnifying lens was used to visually inspect the skin, particularly skin-folds around the eyes, mouth, and vent, for the presence of ectoparasites. Presence or absence of ectoparasites was determined for each individual and the percentage of infected individuals sampled, or parasite prevalence (Bush et al. 1997), was determined. When present, live ectoparasites were collected for subsequent species identification using published keys and then stored for possible future molecular analyses to determine invertebrate vectors involved in snake parasitism.

\section{Hemoparasites}

Hemoparasite prevalence in snakes was assessed using both microscopy and molecular techniques. A 1-mL heparinized syringe with a 25-gauge needle was used to collect $<0.1 \mathrm{~mL}$ of blood from the caudal vein of each snake and a small drop of blood was immediately used to create a blood smear. Blood smears were allowed to air dry at ambient temperature in the field and then transported to the laboratory where slides were fixed in absolute methanol for $10 \mathrm{~min}$ and then stained using a modified Giemsa method (Bennett 1970). Stained smears were cleared with xylene, allowed to air dry, and then cover-slipped and sealed using Cytoseal 60 (VWR, San Francisco, CA). To confirm the presence or absence of hemoparasites, each blood smear was analyzed under $1000 \times$ magnification using a light microscope (Model BX40, Olympus, Center Valley, PA) attached to a digital camera (Infinity-1, Lumenera, Ottawa, ON, Canada). Hemoparasites were identified to genus using a published key (Telford 2009) and then hemoparasite prevalence was determined for each snake by surveying blood smears for 5 min under $600 \times$ magnification. 


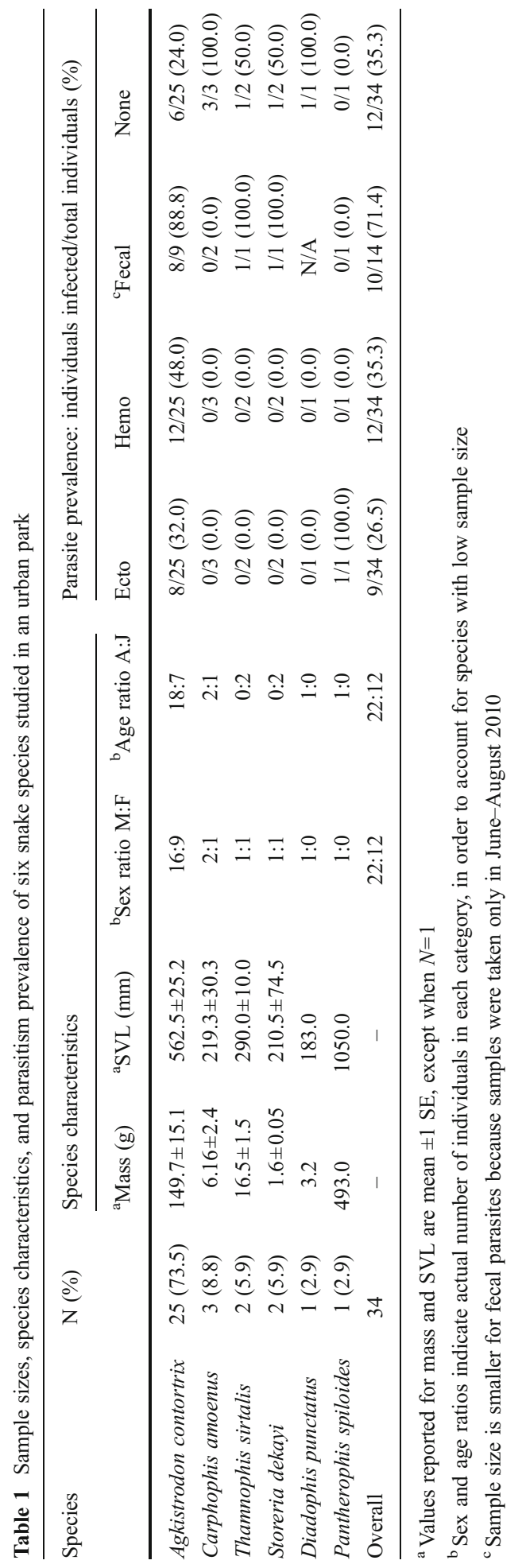


The remainder of each blood sample was placed onto a DNA collection card (model FP705, Fitzco, Inc., Spring Park, Minnesota) for stable storage until molecular analyses were completed. To confirm the genus and to identify the species of hemoparasites, genomic DNA was extracted from blood samples on DNA cards using DNeasy Blood and Tissue kit (Qiagen, Valencia, CA), following the manufacturer's instructions. To detect the presence of hemoparasites of the Hepatozoon spp., a Polymerase Chain Reaction (PCR) was used to amplify the 18S RNA gene of Hepatozoon spp. as described previously (Harris et al. 2011). Briefly, a nested PCR reaction with primers HEMO1 and HEMO2 (Perkins and Keller 2001), and then primers HEPF300 and HEPR900 (Ujvari et al. 2004), were used for Hepatozoon species confirmation and identification. PCR products were isolated and purified using Ultra Clean GelSpin DNA purification kit (MO BIO, Carlsbad, CA) and PCR product sequencing was performed at the University of Tennessee Health Science Center Molecular Resource Center. A BLAST search was performed to match the product sequence to that of a known hemoparasite species.

\section{Fecal parasites}

In 2010 analyses of fecal samples were undertaken to identify fecal parasite genera and prevalence in snakes at Overton Park. Samples were collected from 14 snakes by gently palpating the intestines toward the vent until feces were produced and then placed in a plastic bag until fecal floats were produced. In the laboratory, a 0.15-mg sample of each fresh fecal sample was placed in a 2-mL centrifuge vial, $0.2 \mathrm{~mL}$ of a 1:10 ratio solution of Lugol's iodine to deionized water was added (to improve visualization of parasites and their ova), and a sodium nitrate solution (Fecasol solution, Vetoquinol USA, Inc., Buena, New Jersey) was added to fill the vial. A cover-slip was placed on top of the vial in contact with the solution and after a 20-min incubation period, the cover slip was removed and placed on a glass microscope slide. Fecal floats were analyzed under $1000 \times$ magnification using light microscopy to determine the presence and absence of fecal parasites or their ova, which were identified using a published key (Klingenberg 1993). Fecal parasite prevalence for all genera detected in fecal samples was then determined for each snake by surveying fecal floats for 5 min under $200 \times$ magnification. Total fecal parasite prevalence reported herein reflects the sum prevalence of the types of fecal parasites; thus, presence of any fecal parasite is reported as positive for fecal parasites.

\section{Statistical analyses}

A Chi-Square test was used to test whether ectoparasite and hemoparasite infection prevalences were related in the snakes. Fisher's exact tests were used to determine ectoparasite or Hepatozoon spp. infection differed between sexes, age classes (adult or juvenile), or BCI (positive or negative). Fecal parasitism was not evaluated statistically due to low sample size. Statistical significance was confirmed at $P<0.05$ for all analyses.

\section{Spatial analysis}

Locations of snakes were plotted (Fig. 1c) using ArcGIS 9.3 (ESRI 2008). Satellite imagery from ArcGIS Online (www.arcgis.com) was used to delineate the forest boundaries of Overton Park and to measure distance from each snake to the forest edge, to the closest neighboring snake, and to the closest neighboring snake infected with ectoparasites, Hepatozoon spp., and fecal parasites, or a combination of the three. Mann-Whitney U-tests were 
used to test whether infected and non-infected snakes differed in their distance to the forest edge.

Risk maps (Ostfeld et al. 2005) were created by interpolating the presence of Hepatozoon spp. and ectoparasites across the entire area of the forest fragment, based on the presence of these parasites in the snakes, using the geo-statistical method of kriging with the Spatial Analyst extension for ArcGIS 9.3. Kriging is commonly used to map and predict the spread of disease (Moore and Carpenter 1999; Kleinschmidt et al. 2000; Booth and Dunne 2004). The data for fecal parasites were not interpolated due to low sample size.

\section{Results}

\section{Snake community}

We studied 34 snakes of six species including copperhead (A. contortrix), eastern worm (Carphophis amoenus), eastern garter (Thamnophis sirtalis), brown (Storeria dekayi), southern ringneck (Diadophis punctatus), and rat (Pantherophis spiloides) snakes (Table 1). The capture rate was 0.03 snakes per sampling hour, and only one individual copperhead was recaptured during the study period. Snakes in this urban forest spanned a five-fold range in SVL and a 318-fold difference in body mass from the smallest juvenile brown snake to the largest adult ratsnake. Overall, the snake community was male-biased with 1.8 males for every female and similarly, adult snakes were 1.8 times more common than juveniles in the community (Table 1). Copperhead snakes were the dominant species in the urban forest representing $73.5 \%$ of the total, whereas no other species was detected more than three times (Table 1).

\section{Parasite community}

One type of ectoparasite, a snake mite, was found on some snakes (Fig. 2a). The identity of this ectoparasite remains under investigation. In fecal floats, two protozoa were identified: Entamoeba spp. and Trichomonas spp., both at the trophozoite developmental stage. Also, nematode larvae (Strongloides spp.) were detected (Fig. 2b). Other helminth found in the fecal floats could not be identified reliably in the current study. Histological analysis of blood samples revealed one type of Hemogregarine identified as Hepatozoon spp. (Fig. 2c). This hemoparasite was only found in the copperheads, and 12 of the 25 (48.0\%) copperheads sampled had Hepatozoon spp. detected in their blood (Table 1). Molecular analysis was performed on the hemoparasite to attempt to identify the species (Fig. 2d). The sequence of the $1,000 \mathrm{bp}$ PCR product lead to $88 \%$ query coverage of the Hepatozoon $18 \mathrm{~S}$ rRNA gene. However, a species match with a maximal identity value higher than $94 \%$ was not found.

In the urban forest, $64.7 \%$ of the snakes that were sampled had one or more type of parasites (Fig. 1c; Table 1). $76.0 \%$ of copperheads were infected by at least one parasite type, but of the other five species, only $55.6 \%$ of individuals were infected (Table 1 ). Of the 34 snakes, 12 (35.3\%) had Hepatozoon spp. and 9 (26.5\%) had ectoparasites. Of the 14 snakes sampled for fecal parasites, $10(71.4 \%)$ were positive. Nine snakes were infected with hemoparasites only, four with fecal parasites only, and two with ectoparasites only (Fig. 1c). There were seven instances of co-infections and of these, four had fecal and ectoparasites, one had hemo- and ectoparasites, and two had all parasites present (Fig. 1c). Hepatozoon spp. infection in a snake was not related to whether or not a snake had 

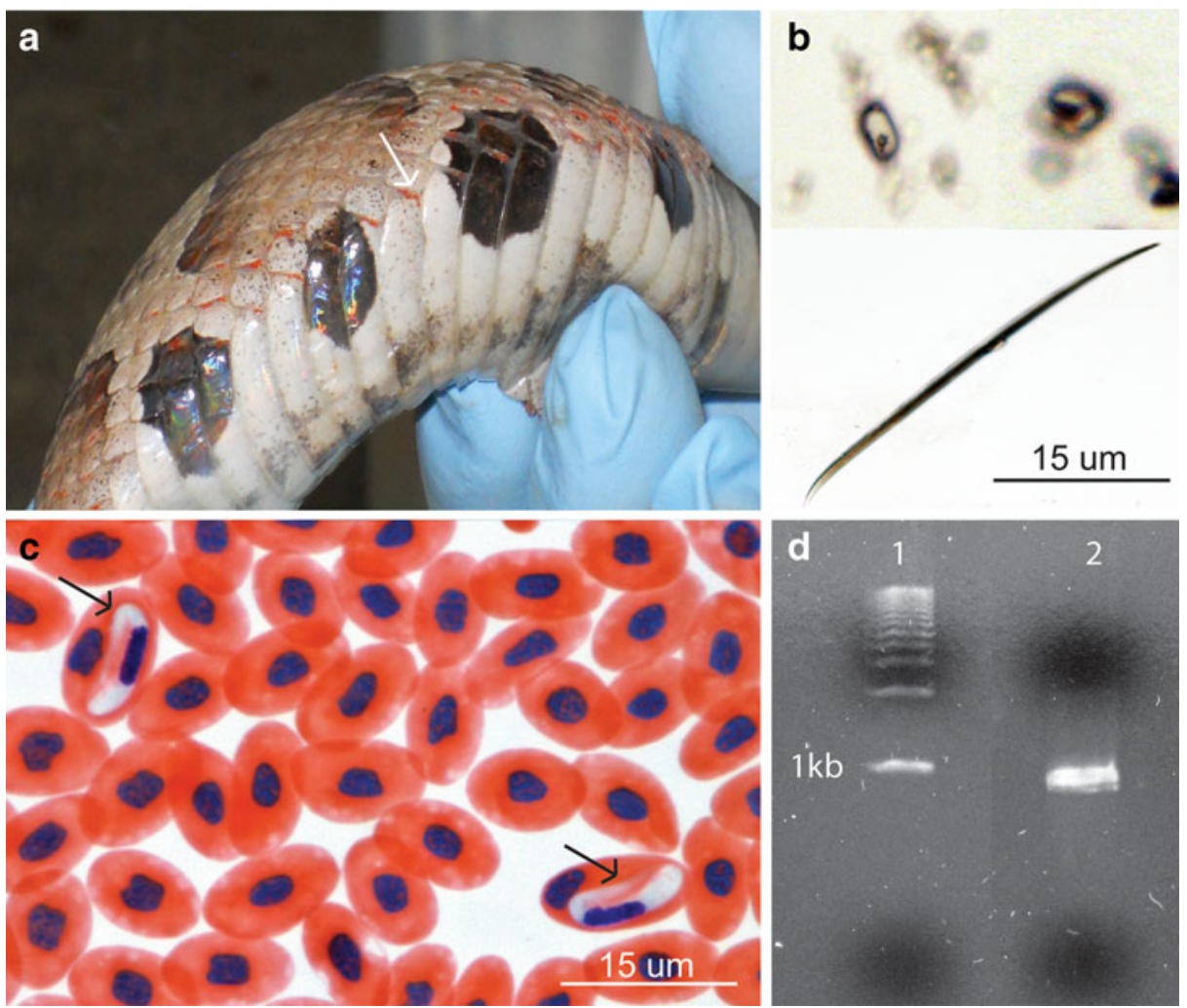

Fig. 2 Identified snake parasites. a Ectoparasite (white arrow); snake mite, b Fecal parasites (clockwise); Entamoeba, Trichomonas, and Strongyloides spp., c Blood smear showing hemoparasites (black arrows); Hepatozoon spp., d Molecular analysis of hemoparasite; lane 1 molecular ladder, lane 2 PCR product for the 18S rRNA gene of Hepatozoon spp

ectoparasites $\left(\chi^{2}=0.021 ; P>0.1\right)$, nor was Hepatozoon spp. infection different between sexes $(P=0.27)$, age classes $(P=0.14)$, or BCI $(P=0.14)$. Similarly, ectoparasite infection did not differ between sexes $(P=0.68)$ or age classes $(P=0.44)$, however, ectoparasites were more common in snakes with positive body condition $(P=0.019)$.

Parasites were detected in 2008, 2009 and 2010 in snakes in the urban forest; however, the percentage of infected individuals was not consistent throughout the study (Table 2). Ectoparasites were found on snakes only in 2008 ( 1 of 4 snakes; $25.0 \%$ ) and 2010 (8 of 15 snakes; $53.3 \%$ ); no ectoparasites were detected in 2009 ( 0 of 15 snakes). Hepatozoon spp. was detected in 2008 (3 of 4 snakes; $75.0 \%$ ), 2009 (7 of 15 snakes; $46.7 \%$ ), and 2010 (2 of 15 snakes; $13.3 \%$ ).

Spatial analyses

Snakes were not encountered uniformly across the urban forest fragment (Fig. 1b), but the snakes' locations did vary with time (e.g., samples from the northwestern section of the forest fragment represent data from 2008, 2009 and 2010). Mean distance ( \pm standard error) of the snakes to the forest edge was $94.8 \mathrm{~m}( \pm 9.4)$, and distances to the nearest snake neighbors and to the nearest snakes infected with Hepatozoon spp., ectoparasites, or fecal parasites varied (Table 3). Snakes with fecal parasites were closer to the forest edge than 
Table 2 Temporal distribution of snake and parasite samples

\begin{tabular}{|c|c|c|c|c|c|}
\hline \multirow[t]{2}{*}{ Year } & \multirow[t]{2}{*}{ Month } & \multirow[t]{2}{*}{ Snakes caught } & \multicolumn{3}{|c|}{ Parasite prevalence: individuals infected/total individuals } \\
\hline & & & Ecto & Hemo & ${ }^{\mathrm{a}}$ Fecal \\
\hline 2008 & ${ }^{\mathrm{b}}$ September & 4 & $1 / 4$ & $3 / 4$ & $\mathrm{~N} / \mathrm{A}$ \\
\hline \multirow[t]{4}{*}{2009} & ${ }^{\mathrm{b}}$ April & 4 & $0 / 4$ & $2 / 4$ & $\mathrm{~N} / \mathrm{A}$ \\
\hline & ${ }^{\mathrm{b}}$ May & 7 & $0 / 7$ & $5 / 7$ & $\mathrm{~N} / \mathrm{A}$ \\
\hline & September & 3 & $0 / 3$ & $0 / 3$ & $\mathrm{~N} / \mathrm{A}$ \\
\hline & October & 1 & $0 / 1$ & $0 / 1$ & $\mathrm{~N} / \mathrm{A}$ \\
\hline \multirow[t]{4}{*}{2010} & May & 1 & $0 / 1$ & $0 / 1$ & $\mathrm{~N} / \mathrm{A}$ \\
\hline & ${ }^{\mathrm{b}}$ June & 2 & $1 / 2$ & $0 / 2$ & $1 / 2$ \\
\hline & ${ }^{\mathrm{b}}$ July & 6 & $4 / 6$ & $2 / 6$ & $6 / 6$ \\
\hline & ${ }^{\mathrm{b}}$ August & 6 & $3 / 6$ & $0 / 6$ & $3 / 6$ \\
\hline
\end{tabular}

\footnotetext{
${ }^{\text {a }}$ Snakes were sampled for fecal parasites June-August 2010
}

${ }^{\mathrm{b}}$ At least one type of parasite was detected during the month

snakes that did not have fecal parasites $(70.7 \mathrm{~m} \pm 14.0$ and $134.5 \mathrm{~m} \pm 22.2$, respectively; $\mathrm{U}=5$; $\mathrm{N}_{1}=10, \mathrm{~N}_{2}=4 ; P=0.036$; Fig. 3). There was no statistical difference in mean distance to forest edge between infected and not infected snakes for Hepatozoon spp. (76.9 m \pm 14.9 and 104.6 $\mathrm{m} \pm 11.7$, respectively; $\left.\mathrm{U}=100 ; \mathrm{N}_{1}=22, \mathrm{~N}_{2}=12 ; P=0.26\right)$ or ectoparasites $(91.2 \mathrm{~m} \pm$ 16.8 and $96.1 \mathrm{~m} \pm 11.4$, respectively; $\mathrm{U}=112.00 ; \mathrm{N}_{1}=25, \mathrm{~N}_{2}=9 ; P=1.00$ ).

Interpolation of Hepatozoon spp. and ectoparasites in Overton Park produced two different risk maps (Figs. 4a and b). The prevalence of Hepatozoon spp. is predicted to be greater in the northwestern corner of the map; however, this area of the park is predicted to have some of the lowest prevalence for ectoparasites.

\section{Discussion}

The six species encountered during this study represented $46.2 \%$ of the 13 species predicted to occur in the area (Scott and Redmond 2008). Snakes in this study were of normal body mass and SVL for their species (Gibbons and Dorcas 2005), suggesting that inhabiting the urban forest has no significant consequences on body size of these species. The sex and age demographics of the urban forest snake community were driven primarily by copperhead snakes, which represented $73.5 \%$ of snakes encountered during this study. Copperheads were most likely encountered far more than other species because copperheads are relatively large sitand-wait predators that spend more time on the substrate than other species (Gibbons and Dorcas 2005). For example, ratsnakes are also large but are arboreal, making them less conspicuous during walking surveys. Moreover, brown, eastern worm, and southern ringneck snakes are fossorial and relatively small, thus making them more difficult to detect (Gibbons and Dorcas 2005). Future studies will include additional surveys to acquire more even sampling amongst species, which will enable intraspecific comparisons of parasitism prevalence.

A type of snake mite was the only ectoparasite detected and it was found almost exclusively on copperhead snakes, the only pit-viper in the urban forest (Table 1). Surprisingly, no ticks were found on snakes in this study despite an abundance of these ectoparasites in the urban forest and the potential for ticks to parasitize snakes (Aubret et al. 2005; Pandit et al. 2011). Nearly $50 \%$ of copperheads were infected with Hepatozoon spp. (Table 1), yet no other snake species studied was 
Table 3 Distance metrics for 34 snakes, indicating the snakes' proximity to the forest edge and proximity to other snakes

\begin{tabular}{|c|c|c|c|c|c|}
\hline & $\begin{array}{l}\text { Distance to } \\
\text { forest edge } \\
(\mathrm{m})\end{array}$ & $\begin{array}{l}\text { Distance to } \\
\text { nearest snake } \\
\text { neighbor }(\mathrm{m})\end{array}$ & $\begin{array}{l}\text { a Distance to nearest } \\
\text { snake with } \\
\text { Hepatozoon spp. (m) }\end{array}$ & $\begin{array}{l}{ }^{a} \text { Distance to nearest } \\
\text { snake with } \\
\text { ectoparasites }(\mathrm{m})\end{array}$ & $\begin{array}{l}{ }^{\text {a }} \text { Distance to nearest } \\
\text { snake with fecal } \\
\text { parasites (m) }\end{array}$ \\
\hline Min & 0.0 & 4.7 & 16.0 & 3.8 & 4.0 \\
\hline $\operatorname{Max}$ & 226.0 & 214.1 & 492.1 & 340.8 & 462.6 \\
\hline Mean & 94.8 & 59.7 & 131.6 & 120.4 & 153.3 \\
\hline SE & 9.4 & 8.7 & 20.3 & 15.3 & 41.8 \\
\hline
\end{tabular}

${ }^{\text {a }}$ Not including self

infected. However, Hepatozoon spp. infections have been documented in non-viperid snakes including water pythons (Liasis fuscus) (Ujvari et al. 2004) and Australian keelback snakes (Tropidonophis mairii) (Shilton et al. 2006) at much greater prevalence than reported here (90 to $100 \%$ ). Fecal parasites were detected in 3 of 5 species examined. Of the three parasite types measured (fecal, hemo- and ectoparasites), fecal prevalence was the greatest (71.4\%), and it was similar to fecal parasite prevalence (54\%) in the striped swamp snake (Regina alleni) (Franz 1977).

The factors that influence parasitism in snakes vary dramatically. For example, aside from ectoparasites and body condition, parasite prevalence was not related to sex, age, or body condition in this study, which corresponds to earlier studies that failed to demonstrate differences in parasitism due to age (Sperry et al. 2009), sex (Shine et al. 1998; Madsen et al. 2005; Sperry et al. 2009), or body condition (Sperry et al. 2009). In contrast, other studies have demonstrated greater hemoparasite prevalence in juvenile water pythons and those with below-average BCI (Madsen et al. 2005) and greater ectoparasite prevalence in adult male ball pythons (Python regius) (Aubret et al. 2005). The effects of snake parasites on their hosts are equally variable. Hepatazoon spp. infection decreases BCI of adult water pythons as well as growth rate and survival of juvenile water pythons (Madsen et al. 2005) and can impair immune function in the same species (Ujvari and Madsen 2005). In other snakes, parasitism has

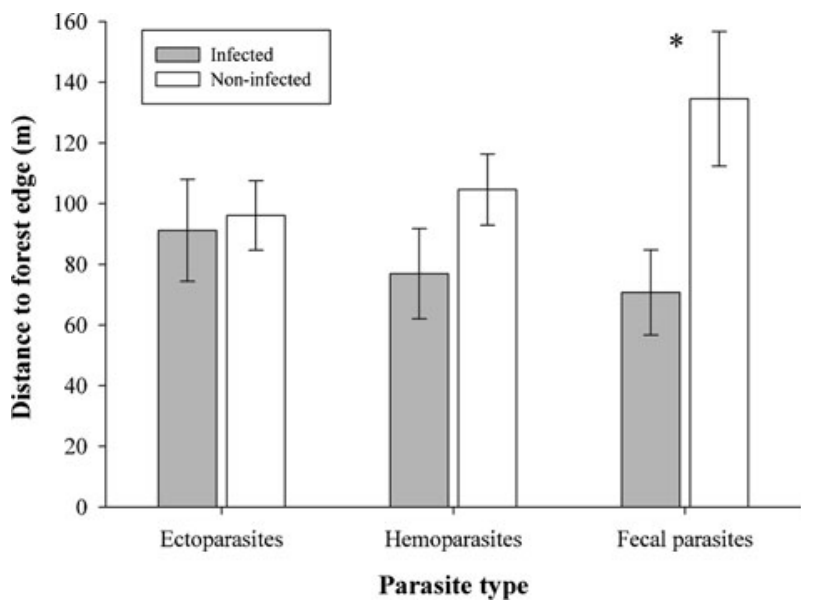

Fig. 3 Non-infected snakes tended to have greater mean distances to the forest edge, however the difference between infected and non-infected snakes was not significant for ecto- or hemoparasites, yet was significant for fecal parasites 

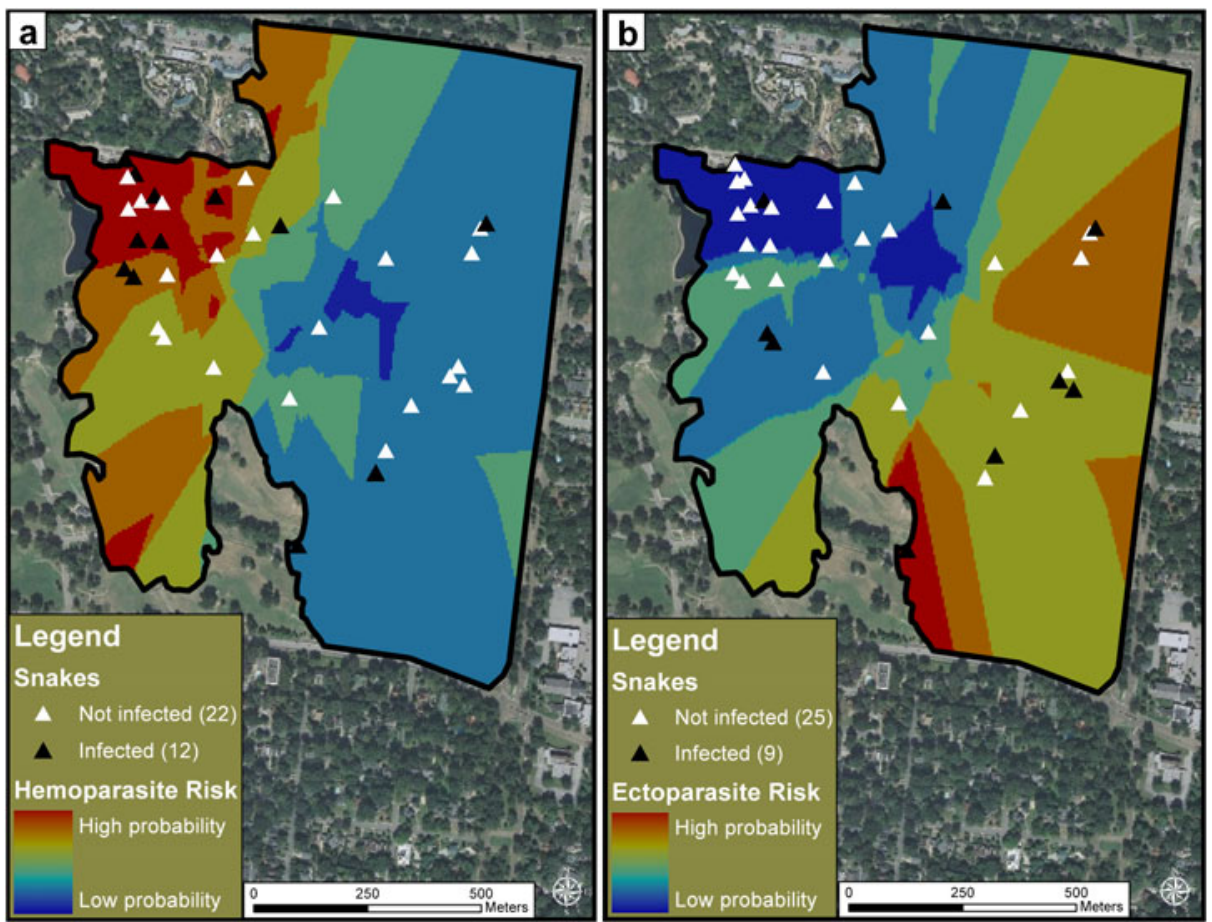

Fig. 4 Risk maps for a Hepatozoon spp. and $\mathbf{b}$ ectoparasites, based on the prevalence of these two parasite types in 34 snakes in the urban forest fragment of Overton Park. Areas predicted to have greater potential for infected snakes vary depending on the parasite type

apparent severe effects on neither body condition (Shilton et al. 2006; Sperry et al. 2009) nor other measures of host fitness including growth rate, feeding rate, locomotor performance, and reproductive output (Shilton et al., 2006). Long-term population- or community-level studies may elucidate whether parasitism, or a combination of parasitism and the possible secondary stress of urbanization, affect host fitness in snakes inhabiting the urban forest.

Spatial analysis indicated that snakes infected with fecal parasites were closer to the forest edge than snakes that were not infected. Although mean distance to the forest edge for snakes infected with Hepatozoon spp. was $76.9 \mathrm{~m}$ and mean distance for those not infected was $104.6 \mathrm{~m}$, the means were not statistically different; however, snakes with Hepatozoon spp. were at greater concentration in the northwestern section of the park. This area of the park is close to Rainbow Lake, a human-made, 1-ha lake that is directly below the Memphis Zoo. In order to determine whether these two variables contribute to the prevalence of Hepatozoon spp. in this area of the forest, we would need to collect additional snakes from the perimeter of the park, closer to Rainbow Lake, and on the eastern border of the Memphis Zoo. The risk maps for Hepatozoon spp. and ectoparsites (Fig. 4a and b) were not similar in interpolating the prevalence of these types of parasites in the urban forest. The lack of similarity suggests that these parasites are driven by different vectors (and potentially different environmental conditions), and that snakes infected by Hepatozoon spp. are not more likely to have ectoparasites.

Prior to this study, little was known about snake parasitism in an urban old-growth forest. The abundance and diversity of snakes in the forest, coupled with high overall parasite prevalence ( $64.7 \%$ hosted at least one parasite), confirm that snakes can be important hosts, 
or possibly reservoirs, facilitating parasite transmission in urban environments. Parasites respond to environmental changes and, with the appropriate experimental design, can be used as bio-indicators of ecosystem health (Vidal-Martínez et al. 2010). This study provides 1) a baseline of understanding of the snake parasite community in an urban forest, and 2) an integrated multi-disciplinary approach that may be used for monitoring the health of the ecosystem in this and other urban forest parks.

\section{Future directions}

Following this preliminary survey, further analysis is required to fully characterize the parasite community. For example, although important for the detection and control of helminth infections, fecal sampling seldom provides a definitive identification of the worm. Therefore, snake necropsies will be required for reliable helminth identification. Moreover, the molecular analysis performed on the hemoparasite could not determine the Hepatozoon species, suggesting that the copperheads in Overton Park may be infected with a yet to be described Hepatozoon spp. To confirm the species, greater coverage of the 18S rRNA gene is required, as well as amplification of other genomic regions such as the mitochondrial cytochrome $b$ gene and the internal transcribed spacer (ITS) region or both. In addition, snake necropsies would be crucial to determine developmental stages and the identification of the vector required to fully characterize the Hepatozoon species. The ectoparasite remains to be identified. For this, better sample preservation will be required at the moment of capture.

It is important to integrate landscape ecology with epidemiology in order to better understand the interactions among vectors, hosts, potential reservoirs, and transmission (Ostfeld et al. 2005). A greater sample size, distributed across the entire park, would help us determine to what extent the different types of parasites are found in the park. Furthermore, a greater sample size would allow us to investigate the extent to which the urban landscape (e.g., forest disturbance, water bodies, vector prevalence) influences parasite prevalence. Future data will be used to: 1) test the reliability of our current risk maps, 2) determine the minimum sample size needed in order to accurately predict parasite prevalence, and 3) further investigate the landscape variables that influence parasite prevalence and transmission.

Acknowledgments We thank the Rhodes Fellowship for funding this project, Kimber Jones, Matt McCravy, and Alex Yu for assistance in the lab, and one anonymous reviewer for feedback on an earlier version of this manuscript. Special thanks to the Tennessee Natural Resources Agency and the City of Memphis for site access. This research was conducted in accordance with Rhodes IACUC \# 099 and Tennessee Wildlife Resources Agency Permit \# 3506.

Conflict of interest The authors declare that they have no conflict of interest.

Open Access This article is distributed under the terms of the Creative Commons Attribution License which permits any use, distribution, and reproduction in any medium, provided the original author(s) and the source are credited.

\section{References}

Aubret F, Bonnet X, Shine R, Lourdais O (2002) Fat is sexy for females but not males: the influence of body reserves on reproduction in snakes (Vipera aspis). Horm Behav 42:135-147

Aubret F, Bonnet X, Harris M, Maumelat S (2005) Sex differences in body size and extoparasite load in the ball python, Python regius. J Herpetol 39:315-320

Bennett GF (1970) Simple techniques for making avian blood smears. Can J Zool 48:585-586 
Blair RB (2001) Creating a homogenous avifauna. In: Marzluff JM, Bowman R, Donnelly R (eds) Avian ecology and conservation in an urbanizing world. Kluwer, Norwell, pp 459-486

Booth M, Dunne DW (2004) Spatial awareness in parasite immuno-epidemiology. Parasite Immunol 26:499_ 507

Bradley CA, Altizer S (2007) Urbanization and the ecology of wildlife diseases. Trends Ecol Evol 22:95-102

Brown GP, Shilton CM, Shine R (2006) Do parasites matter? Assessing the fitness consequences of haemogregarine infection in snakes. Can J Zool 84:668-676

Burger J, Jeitner C, Jensen H, Fitzgerald M, Carlucci S, Shukla S, Burke S, Ramos R, Gochfeld M (2004) Habitat use in basking Northern water (Nerodia sipedon) and Eastern garter (Thamnophis sirtalis) snakes in urban New Jersey. Urban Ecosyst 7:17-27

Bush AO, Lafferty KD, Lotz JM, Shostak AW (1997) Parasitology meets ecology on its own terms: Margolis et al. revisited. J Parasitol 83:575-583

Chace JF, Walsh JJ (2006) Urban effects on native avifauna: a review. Landsc Urban Plan 74:46-69

Deviche P, Greiner EC, Manteca X (2001) Seasonal and age-related changes in blood parasite prevalence in dark-eyed juncos (Junco hyemalis, Aves, Passeriformes). J Exp Zool 289:456-466

Ditchkoff SS, Saalfeld ST, Gibson CJ (2006) Animal behavior in urban ecosystems: modifications due to human-induced stress. Urban Ecosyst 9:5-12

ESRI (2008) ArcGIS 9.3. ESRI, Redlands

Faeth SH, Warren PS, Shochat E, Marussich WA (2005) Trophic dynamics in urban communities. Bioscience 55:399-407

Franz R (1977) Observations on the food, feeding behavior, and parasites of the striped swamp snake, Regina alleni. Herpetologica 33:91-94

Gibbons W, Dorcas M (2005) Snakes of the Southeast. University of Georgia Press, Athens

Greene HW (1997) Snakes, the evolution of mystery in nature. University of California Press, Berkeley

Harris DJ, Maia JP, Perera A (2011) Molecular characterization of Hepatozoon species in reptiles from the Seychelles. J Parasitol 97:106-110

Keesing F, Belden LK, Daszak P, Dobson A, Harvell CD, Holt RD, Hudson P, Jolles A, Jones KE, Mitchell CE, Myers SS, Bogich T, Ostfeld RS (2010) Impacts of biodiversity on the emergence and transmission of infectious diseases. Nature 468:647-652

Kleinschmidt I, Bagayoko M, Clarke GP, Le Sueur D (2000) A spatial statistical approach to malaria mapping. Int J Epidemiol 29:355-361

Klingenberg RJ (1993) Understanding reptile parasites: a basic manual for herpetoculturists and veterinarians. Advanced Vivarium Systems, Lakeside

Leonard ML, Horn AG (2008) Does ambient noise affect growth and begging call structure in nestling birds? Behav Ecol 19:502-507

LoGiudice K, Ostfeld RS, Schmidt KA, Keesing F (2003) The ecology of infectious disease: effects of host diversity and community composition on Lyme disease risk. Proc Natl Acad Sci USA 100:567-571

Madsen T, Ujvari B, Olsson M (2005) Old pythons stay fit; effects of haematozoan infection on life history traits of a large tropical predator. Oecologia 142:407-412

Marcogliese DJ (2005) Parasites of the superorganism: are they indicators of ecosystem health? Int J Parasitol 35:705-716

Marzluff JM (2001) Worldwide urbanization and its effects on birds. In: Marzluff JM, Bowman R, Donnelly R (eds) Avian ecology and conservation in an urbanizing world. Kluwer, Norwell, pp 19-47

McKinney ML (2008) Effects of urbanization on species richness: a review of plants and animals. Urban Ecosyst 11:161-176

Mendes S, Colino-Rabanal VJ, Peris SJ (2011) Bird song variations along an urban gradient: the case of the European blackbird (Turdus merula). Landsc Urban Plan 99:51-57

Moore DA, Carpenter TE (1999) Spatial analytical methods and geographic information systems: use in health research and epidemiology. Epidemiol Rev 21:143-161

Moore IT, Greene MJ, Mason RT (2001) Environmental and seasonal adaptations of the adrenocortical and gonadal responses to capture stress in two populations of the male garter snake, Thamnophis sirtalis. J Exp Zool 289:99-108

NLCD 2001 National Land Cover Dataset. U.S. Geological Survey http://www.mrlc.gov/nlcd_definitions.php Accessed 15 July 2011

Ostfeld RS, Glass GE, Keesing F (2005) Spatial epidemiology: an emerging (or reemerging) discipline. Trends Ecol Evol 20:328-336

Page LK, Gehrt SD, Robinson NP (2008) Land-use effects on prevalence of raccoon roundworm (Baylisascaris procyonis). J Wild Dis 44:594-599

Pandit P, Bandivdekar R, Geevarghese G, Pande S, Mandke O (2011) Tick infestation on wild snakes in northern part of Western Ghats of India. J Med Entomol 48:504-507

Parris KM (2006) Urban amphibian assemblages at metacommunities. J Anim Ecol 75:757-764 
Pattishall A, Cundall D (2009) Habitat use by synurbic watersnakes (Nerodia sipedon). Herpetologica 65:183-198

Perkins SL, Keller AK (2001) Phylogeny of nuclear small subunit rRNA genes of hemogregarines amplified with specific primers. J Parasitol 87:870-876

Preston D, Johnson P (2010) Ecological consequences of parasitism. Nat Educ Knowl 1:39

Randa LA, Yunger JA (2006) Carnivore occurrence along an urban-rural gradient: a landscape-level analysis. J Mammal 87:1154-1164

Riley SPD, Sauvajot RM, Fuller TK, York EC, Kamradt DA, Bromley C, Wayne RK (2003) Effects of urbanization and habitat fragmentation on bobcats and coyotes in southern California. Conserv Biol 17:566-576

Riley SPD, Busteed GT, Kats LB, Vandergon TL, Lee LFS, Dagit RG, Kerby JL, Fisher RN, Sauvajot RM (2005) Effects of urbanization on the distribution and abundance of amphibians and invasive species in southern California streams. Conserv Biol 19:1894-1907

Rubbo MJ, Kiesecker JM (2005) Amphibian breeding distribution in an urbanized landscape. Conserv Biol 19:504-511

Schoech SJ, Bowman R (2001) Variation in the timing of breeding in two Florida scrub-jay (Aphelocoma coerulescens) populations: do physiologic measures reflect different environments? In: Marzluff JM, Bowman R, Donnelly R (eds) Avian ecology and conservation in an urbanizing world. Kluwer, Norwell, pp 289-306

Scott AF, Redmond WH (2008) Atlas of reptiles in Tennessee. The center for field biology. Austin Peay State University, Clarksville, http://apsu.edu/reptatlas/ Accessed 08

Shilton CM, Shine R, Brown GP (2006) Do parasites matter? Assessing the fitness consequences of haemogregarine infection in snakes. Can J Zool 84:668-686

Shine R, Koenig J (2001) Snakes in the garden: an analysis of reptiles "rescued" by community-based wildlife careers. Biol Conserv 102:271-283

Shine R, Harlow PS, Keough JS, Boeadi (1998) The influence of sex and body size on food habits of a giant tropical snake, Python reticulates. Funct Ecol 1998:248-258

Shochat E, Warren PS, Faeth SH, McIntyre NE, Hope D (2006) From patterns to emerging processes in mechanistic urban ecology. Trends Ecol Evol 21:186-191

Slabbekoorn H, Ripmeester EAP (2008) Birdsong and anthropogenic noise: implications and applications for conservation. Mol Ecol 17:72-83

Smith JJ, Goode M, Amarello M (2009) Changes in structure and composition of Sonoran Desert reptile communities associated with golf courses. In: Mitchell JC, Brown REJ, Batholomew B (eds) Urban herpetology. Society for the Study of Amphibians and Reptiles, Salt Lake City, pp 311-320

Sperry JH, Butler LK, Romero LM, Weatherhead PJ (2009) Effects of parasitic infection and radio-transmitters on condition, hematological characteristics and corticosterone concentrations in Texas ratsnakes. J Zool 278:100-107

Telford SR (2009) Hemoparasites of the Reptilia: color atlas and text. CRC Press, Boca Raton

Ujvari B, Madsen T (2005) Age, parasites, and condition affect humoral immune response in tropical pythons. Behav Ecol 17:20-24

Ujvari B, Madsen T, Olsson M (2004) High prevalence of Hepatozoon spp. (Apicomplexa, Hepatozoidae) infection in water pythons (Liasis fuscus) from tropical Australia. J Parasitol 90:670-672

United Nations, Department of Economic and Social Affairs, Population Division (2010) World urbanization prospects, the 2009 revision: Highlights. United Nations, New York

Vidal-Martínez VM, Pech D, Sures B, Purucker T, Poulin R (2010) Can parasites really reveal environmental impact? Trends Parasitol 26:44-51

Vignoli L, Mocaer I, Luiselli L, Bologna MA (2009) Can a large metropolis sustain complex herpetofauna communities? An analysis of the suitability of green space fragments in Rome. Anim Conserv 12:456-466

Vitt LJ, Caldwell JP (2009) Herpetology: an introductory biology of amphibians and reptiles, 3rd edn. Academic, Burlington

Walker JS, Grimm NB, Briggs JM, Gries C, Dugan L (2009) Effects of urbanization on plant species diversity in central Arizona. Front Ecol Environ 7:465-470

Waye HL, Mason RT (2008) A combination of body condition measurements is more informative than conventional condition indices: temporal variation in body condition and corticosterone in brown tree snakes (Boiga irregularis). Gen Comp Endocrinol 155:607-612

Weatherhead PJ, Brown GP (1996) Measurement versus estimation of condition in snakes. Can J Zool 74:1617-1621 